\title{
Covid-19: Projections of mortality in the US rise as states open up
}

\author{
Owen Dyer
}

Montreal

Academics behind the model most cited by the White House in predicting the likely loss of life from covid-19 have nearly doubled their estimate of US mortality over the next three months.

The modellers from the Institute for Health Metrics and Evaluation at the University of Washington said that there are likely to be 134475 deaths from covid-19 (95\% range 95092 to 242890 ) in the US by 4 August, ${ }^{1}$ up from the 90000 that they initially forecast, which they adjusted to 60000 last month. The grimmer outlook takes account of the fact that many lockdowns are now lifting and that the public became more mobile in recent weeks, even before any official easing of restrictions.

In April President Donald Trump offered hope of a final death toll under 60 000. But as deaths passed 65 000, he told Fox News: "We're going to lose anywhere from 75000,80000 to 100000 people." Some states have passed their peak, but in others new cases are surging. The country overall has reached a plateau over the past month, with new US cases averaging about 30000 a day and deaths about 1900 a day.

Scott Gottlieb, former FDA administrator, wrote in the Wall Street Journal, "Social distancing and other measures have slowed the spread. But the halt hasn't brought the number of new cases and deaths down as much as expected or stopped the epidemic from expanding."

A Centers for Disease Control and Prevention (CDC) presentation obtained by the New York Times, intended for a government videoconference, predicted that both cases and deaths per day would continue to increase, not decline as the government claimed. By 1 June, when the model's forecast ends, the US would be seeing about 200000 new cases a day and 3000 deaths a day, it said. ${ }^{2}$ The government denied that the model represented its expectations about the future. A White House task force devoted to reopening the economy has reportedly used a model developed by economist Kevin Hassett, which predicts that deaths will fall to almost zero by 15 May.

White House guidelines demand that, before states loosen restrictions, they develop strong testing infrastructure and report two weeks of decline in daily new case numbers and positive test rates, but these criteria are being widely ignored. Texas is reopening malls, restaurants, and cinemas, and Tennessee is reopening nail salons and fitness centres, yet both states have seen cases spike this week.
Trump has lauded these actions and continued to tweet his support for protesters who have demonstrated against state lockdowns. At one protest in Lansing, Michigan, heavily armed men occupied the state house last week. Anger at the restrictions erupted in violence two days later in Flint, Michigan, when a store security guard was fatally shot after telling a woman that her child needed a mask to enter the shop.

The number of covid-19 deaths that have already been reported-currently 69925 -is most likely an undercount, the CDC has said. Thousands of probable covid-19 deaths that occurred when tests were still largely unobtainable have been excluded from this number. Overall excess mortality so far this year is signalling both uncounted covid-19 deaths from February and $\mathrm{March}^{3}$ and a parallel spike in deaths from other conditions, probably due to delayed care. ${ }^{4}$

In an election year, the death count has become intensely politicised. States' counting methods can vary, and those most eager to lift restrictions tend to publish the most conservative figures. Alabama submits each death to a medical board that sometimes lists other causes of death in patients who died after testing positive for covid-19. ${ }^{3}$ Florida stopped publishing its medical examiners' lists of covid-19 deaths and instead publishes its own, shorter list.

Stephen Nelson, chairman of Florida's Medical Examiners Commission, told the Tampa Bay Times that the state plans to strip the medical examiners' data of case reports and cause of death before releasing it, an unprecedented step. "It's paid for by taxpayer dollars," he said, "and the taxpayers have a right to know."

1 Institute for Health Metrics and Evaluation. Covid-19 projections: predicting the next phase of the epidemic. 4 May 2020. http://www.healthdata.org/covid/updates

2 Covid-19 HHS/FEMA Interagency Videoteleconference. Centers for Disease Control and Prevention Situation Update. May 2020. https://int.nyt.com/data/documenthelper/6926mayhhsbriefing/af7319f4a55fd0ce5dc9/optimized/full.pdf

3 Brown E, Ba Tran A, Reinhard B, Ulmanu M. US deaths soared in early weeks of pandemic, far exceeding number attributed to covid-19. Washington Post 2020 April 27. https://www.washingtonpost.com/investigations/2020/04/27/covid-19-death-tollundercounted/

4 National Center for Health Statistics. Excess deaths associated with covid-19. 29 April 2020. https://www.cdc.gov/nchs/nvss/vsrr/covid19/excess_deaths.htm

5 McGrory K, Woolington R. Florida medical examiners were releasing coronavirus death data. The state made them stop. Tampa Bay Times 29 April 2020. https://www.tampabay. com/news/health/2020/04/29/florida-medical-examiners-were-releasing-coronavirus-deathdata-the-state-made-them-stop/

Published by the BMJ Publishing Group Limited. For permission to use (where not already granted under a licence) please go to http://group.bmj.com/group/rights-licensing/ permissions 